\title{
A Study on College EFL Learning Community Based on QQ International
}

\author{
WEI Li \\ Liaoning Police Academy \\ No. 260 Yingping Road Ganjingzi District, Dalian 116036, China \\ Tel: 86-411-8672-9682 E-mail: weili1972@126.com
}

Received: 17-11- 2012

Accepted: 19-12- 2012

Published: 01-03- 2013

doi:10.7575/aiac.ijalel.v.2n.2p.1

URL: http://dx.doi.org/10.7575/aiac.ijalel.v.2n.2p.1

The research is financed by the Twelfth Five-year Plan for Educational Science Project of Liaoning Province (2012) No. JG12EB082J.

\begin{abstract}
An EFL Learning Community has been set up online via a free messaging tool QQ International to consolidate and apply the knowledge learnt in class. One sub-community aims at developing multicultural awareness while the other focuses on expertise training in English for the undergraduates in several universities. Our innovative approach is that the trainees interact with other participants with virtual icons, virtual roles and specific achievement goals according to curriculum-related scenarios. The project team utilized surveys and observations to analyze the advantages and disadvantages from different perspectives and gain further insight into the nature of member participation, knowledge application and learning interests. Results revealed that EFL Learning Community promoted learning interests and training efficiency, contributed to interprofessional collaboration and interpersonal cooperation, with the implication that levels of moderate anonymity are the most optimal for role-plays in a learning community both online and in real life.
\end{abstract}

Keywords: EFL Learning Community, QQ International, designed scenarios, English learning, expertise training, multiculturalism

\section{Introduction}

Technology revolutionizes learning. Professional Learning Community (PLC) emphasizes the process of learning for improvement and change in schools. A PLC consists of a group of people who take "an active, reflective, collaborative, learning-oriented and growth-promoting approach toward both the mysteries and the problems of teaching and learning" (Mitchell \& Sackney, 2001). In most cases, participants involved in a PLC become more intellectually mature and responsible for their learning. They like to develop the capacity to care about the learning of their peers and are focused on collegiality and professionalism (Manzaro, 2003). Moreover, PLCs offer teachers the possibility to connect with one another within and across the school in order to improve students' learning outcomes and their own professional learning (Roberts \& Pruitt, 2009).

Application of free online programs in after-class e-learning is one of the new trends in recent studies worldwide. The advantages of e-learning include substantial cost savings due to elimination of travel expenses, just-in-time access to timely information, higher retention of content through personalized learning, improved collaboration and interactivity among students, and online training is less intimidating than instructor-led courses (Karen, 2012). New technologies such as Wireless Fidelity (Wi-Fi) and InfraRed allow mobile devices such as laptops and personal digital assistants (PDAs) to access information almost anywhere at any time. A Ubiquitous Learning Environment provides a student with a pervasive setting in which learning can take place, even if the student or learner may not realize that he or she is learning. Learners can use desktop computers, laptops, or mobile devices such as smart cell phones and PDAs (Abdulrahman, 2010).

Studies on computer-assisted instruction in English as a Foreign Language (hereafter referred to as EFL) learning can be traced back to 2001 in Liaoning Police Academy when two multi-media classrooms were built with LAN and the Internet linking 160 computer terminals. EFL learning contains three-semester English for General Purpose (hereafter referred to as EGP) learning and two-semester English for Specific Purpose (hereafter referred to as ESP) learning. Virtual Policing in English (hereafter referred to as VPIE) training for ESP learning, characterized by role-playing of police officers and their service recipients in English, had been practiced on a platform developed with Microsoft Visual Studio 2005 asp.net(c\#) to improve the students' professional skills until a free, more powerful software named QQ came to influence almost every Internet surfer in China around 2009.

Part II of the essay describes the outline, purpose of the study, and the ingredients of the online Community. Part III expounds on the activities involved in the Community, one is for EGP learning and the other is for ESP training. Part IV discusses the findings, implications, limitations and future work of EFL Learning Community. 


\section{Construction of EFL Learning Community}

\subsection{Program Outline}

Virtual Service Learning pedagogy has been conceived and implemented in view of the career focus and English level of the students in Liaoning Police Academy, the program focuses on curriculum learning, scenario-based training, reflections and assessment, aiming at improving their comprehensive English competence to facilitate students' proactive participation in the increasingly demanding work force and providing teachers an easy approach by taking advantages of free messaging online tools rather than a heavy technical workload.

\subsection{Purpose of the Study}

Based on the results of scenario-based classroom training and the seamless English learning in the interactive cyberspace (Zhongwen, 2012; WEI, 2012), we want to probe into approaches of using free online tools to further interactions among students and teachers after class in view of, firstly, a common practice in most of the universities nowadays to shorten EFL instructional time on campus; secondly, an increasingly openness to the access to free online software for students and teachers as well; lastly and most importantly, an especially need to enhance learning interests and training efficiency in network environments.

Online learning community is defined as "a group of people who communicate with each other across the Internet to share information, learn more about a topic, or work on a project of mutual interest" (Porter, 2004). The common features of an online learning community involve learners' gathering, sharing information, collaborating on projects, and proactively participating, which foster cooperation and mutual support rather than encouraging competition found in other team environments such as traditional learning classes (Ziad, 2011). These characteristics make it an excellent supplement to instructional EFL learning. Figure 1 demonstrates the relationships between face-to-face instruction and EFL Learning Community under the framework of Virtual Service Learning:

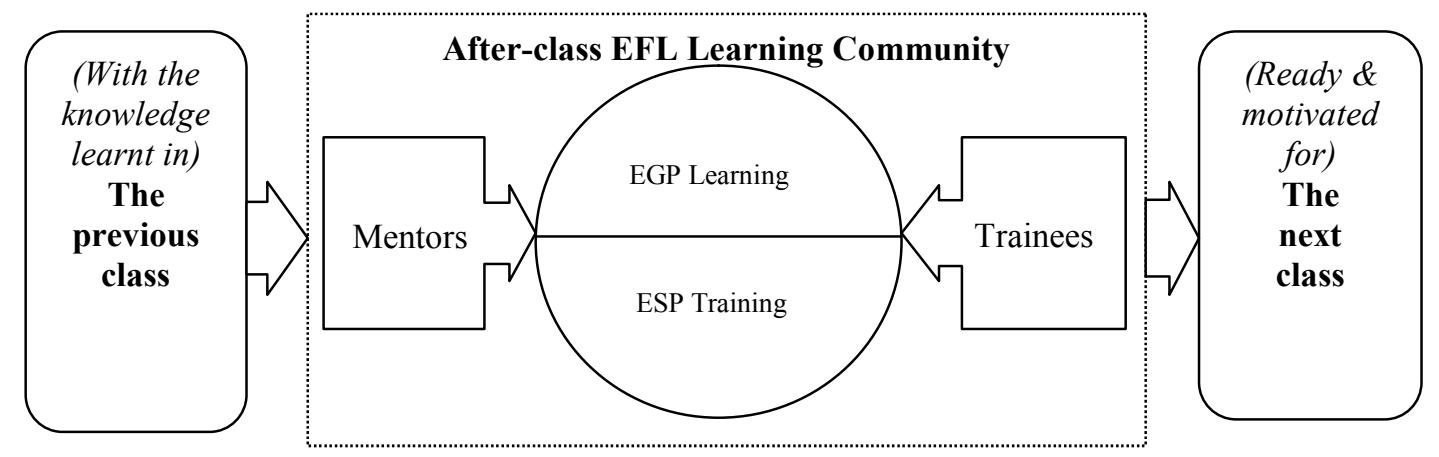

Figure1. Models of Relationships of EFL Community Learning with Classroom Learning

In order to help the students to develop active, collaborative and professional capabilities, we set up EFL Learning Community online, aiming at implementing the essence of professional learning communities and seeking answers to the following research questions:

1. How do the participants like the activities in the Community compared with conventional face-to-face learning activities on campus?

2. How do they like the anonymous training and the authentic identity learning?

3. What does each member benefit as an individual and as a participant from the Community?

4. What role does the Community play in promoting their learning interests, motivations and efficiency?

5. What are the advantages and disadvantages of the Community from a participant's perspective?

\subsection{Tools and Resources}

QQ International 1.2 (hereafter referred to as QQi) is a multi-language instant messenger client that's based on the platform of China's hugely popular chat program QQ. Available in English, Japanese and French, QQi offers a bridge to connect with the existing 700 million Chinese accounts.

One research indicates that the application of QQ chat software can stimulate students' learning motivation and innovation ability, which greatly improves emotional communication between teachers and students; meanwhile, the students are encouraged to participate in follow-up sessions, and teachers are encouraged to build their skills and confidence for teaching (Xingang et al, 2010). Another study combines Blog with QQ group to construct the collaborative learning platform, analyzing the function of the collaborative learning platform, and discusses the implementation process of the platform in the teaching (Qi \& Pingguang, 2012). But there are very few studies on the application of QQi in EFL learning.

We take advantage of typing and voice chat on QQi with other useful tools applied in EFL Learning Community as listed in Table 1 (Zhongwen, 2013): 
Table 1. Functions of QQi Used in EFL Learning Community

\begin{tabular}{|c|c|c|}
\hline Functions of QQi & used in EFL Learning Community to & Advantages \\
\hline $\begin{array}{l}\text { Typing, Voice or } \\
\text { Video Call }\end{array}$ & $\begin{array}{l}\text { communicate with members, learn and } \\
\text { train }\end{array}$ & free and at the participant's choice \\
\hline $\begin{array}{l}\text { Smart Friend } \\
\text { Finder }\end{array}$ & find more participants & worldwide and directly \\
\hline Send Files & $\begin{array}{l}\text { send files instantaneously to another } \\
\text { QQ user }\end{array}$ & more quickly and conveniently \\
\hline Invite Contacts & join the current discussion & $\begin{array}{l}\text { with more participants in a } \\
\text { discussion }\end{array}$ \\
\hline Discussions & show a model training & to the whole group \\
\hline Qzone & $\begin{array}{l}\text { keep the trainee's homework, } \\
\text { messages, feedbacks }\end{array}$ & to be assessed by other participants \\
\hline Screen Capture & send a screenshot to his or her Qzone & to be the evidence of online activities \\
\hline Message History & check discussion contents & $\begin{array}{l}\text { to be assessed in language } \\
\text { proficiency }\end{array}$ \\
\hline Translator & translate Chinese or English & to improve English competence \\
\hline
\end{tabular}

In addition to the Internet resources and the references for the college English textbooks, Multicultural Network for Policing, consisting of STARS model curriculum learning, scenario-based training, student-centered reflections and assessment, was designed and available. Learning resources cover college English involving almost every sphere of human life and English for policing including police administration, police training, criminal technology, criminal investigation, criminal justice, traffic control, cyber crime investigation and international liaison in the form of speaking, listening, writing, reading and translating. Training resources mainly contain scenarios designed in accordance with language points learnt in each unit with characteristics of being vocation-related and multi-disciplinary, curriculum connected, holistic and complete, authentic and complicated. Student-centered reflections are done through various channels like online forum, appeals and surveys to make their comments, suggestions, criticism or reflections conveyed and taken into account. Assessment is a tertiary indexed and quantitative evaluation system to grade a student's performance from 1. Motivation and prospect (weight 0.05), 2. Learning (weight 0.20), 3. Training (weight 0.20), 4. Forum participation (weight 0.05), 5. Reflections (weight 0.05), 6. Homework (weight 0.15), 7. Quiz and test (weight 0.20 ) and 8 . Self-assessment and assessment by others (weight 0.10) (Zhongwen, 2013).

\subsection{Members of the Community}

English is the exclusive communicative language for the Community, students from the Academy and four other universities are classified as trainees while English teachers, major course teachers, foreign teachers and police experts are referred to as mentors, whose responsibilities are to cooperate with, supervise and help the trainees in their English learning, expertise training and evaluate the trainees' performance in the Community.

\section{Activities in EFL Learning Community}

A trainee can study by himself in the Community, practicing with the computer, seeking assistance independently from a mentor, but for most of the time, a trainee is supposed to be a member of the Community by participating activities to interact with other members to better his or her team spirits, interpersonal skills and professional service qualities in English.

\subsection{Growing-up Group for EGP Learning: from the Perspective of Multiculturalism}

Linguistic, cultural, technological and other factors affect interactions in online exchanges in the global age (Kirk, 2007). The author registered a number on QQi as the administrator of the group named Growing-up, aiming at constructing a seamless English learning space to enhance the students' multicultural awareness and professional competence through cultural immersion, interpersonal communication, information sharing, hot issue discussion and problem resolution. The number is distributed among the trainees and mentors to be approved by the administrator when they apply to join the group with a net-name to take part in:

Topic Discussion to strengthen the learning of EGP language points: topics generally derive from the text learnt on the previous class, a case in point is the controversial issue of the contradiction between Chinese and Western learning styles in a text entitled Learning, Chinese Style. To help the students understand different learning systems and educational concepts, the mentors held a heated discussion on the advantages and disadvantages of each system and the appropriate ways we should take in view of the new trend of education development. The administrator uploaded materials about Chinese learning styles and Western learning styles for references as shown in Figure 2. Members of the group had a debate on the issue from different perspectives with the knowledge learnt and the materials available through literal or verbal interactions with people from diverse backgrounds, the trainees and the mentors had deep insights into the sources of two educational systems and the practice of two learning styles, citing grounds of their arguments from the text, the Internet, uploaded files, famous quotations or their personal experiences. 


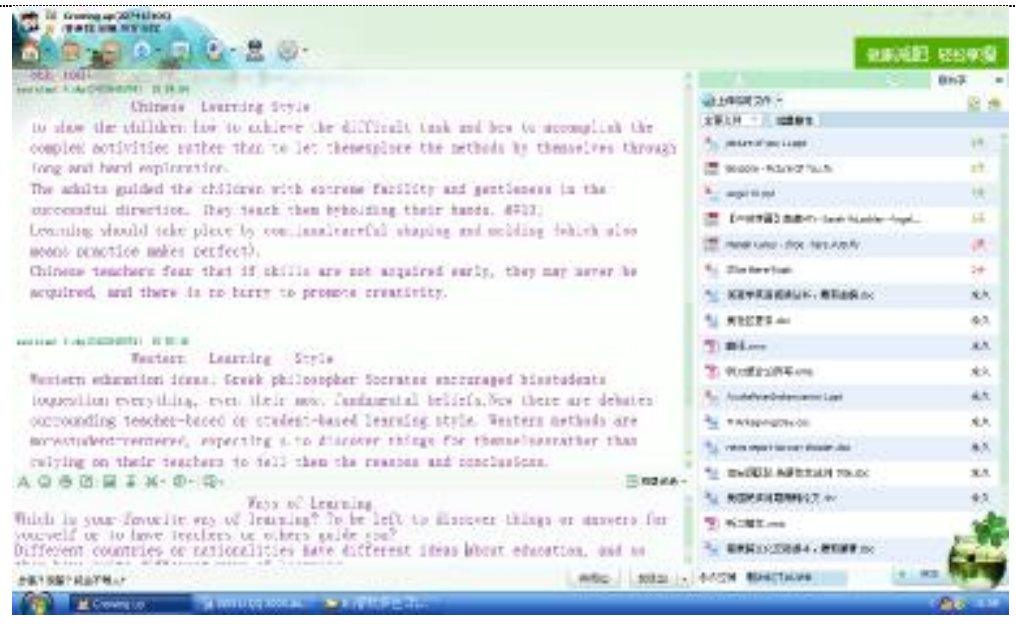

Figure 2. Materials Uploaded for a Discussion on Cultural Diversity

Pop Vane to improve multicultural awareness: to arouse the students' passion for English learning and multicultural awareness, a learning assistant in charge of introducing foreign pop music and movie hits uploads excellent videos or PPT of foreign songs and movies on a weekly basis. He is a student with huge zest for English and foreign cultures, actively shouldering the task of helping group members to improve interests in English through keeping abreast of Western entertainment trends. He has shared with other group members 11 beautiful songs and 11 delicate PPT to match with video image, such as Boyzone, Angel, and Mariah Carey. The pop culture is the vane and pace of a culture, to appreciate the music and movies from other cultural backgrounds is an efficient strategy and a shortcut to increase multicultural awareness among foreign language learners.

Culture Forum to experience cultural diversity: group members including students from Liaoning Police Academy, Nanjing Normal University, Sichuan University, Liaoning Normal University, Dalian Medicine University, learning assistants and foreign teachers or experts constitute a cultural mosaic. Exchanges and cooperation are carried out through chatting room for an open discussion, E-mail system for a private communication, and group sharing for collective exploration. Every member is free to select ways and topics to express, convey or criticize a viewpoint on My Fashion View, The American Dream, The Native Speaker's Situation, The Virtual Life, The Creativity and Imagination etc.

These activities can not only render the learners opportunities to express their attitudes toward foreign cultures, but also help them to understand our own culture from foreigners' perspectives. A culture panorama presented with IT technologies is appealing to the participants and nurturing the soil of language learning.

\subsection{VPIE Group for ESP Training: from the Perspective of Learning by Doing}

VPIE is a trainee-centered police service simulation English learning and training program in which participants conceive, develop and manage virtual police organizations to fulfill their duties and services on a global basis utilizing various web-mediated technologies (Zhongwen, 2007). VPIE emphasizes project-based collaborative learning and training to enhance the trainee's vocational skills and career success by experiencing potential working roles with sustained interests. With some basic terms and expressions on a specific police work, members of the Community can login VPIE group via QQi in which they select a role from the Scenario Base and fulfill a specific task with an icon and a character name, the characters are generally two types, one is police officer with detailed field title, a traffic police officer, a detective, a dispatcher, a patrol officer and so on; the other type is police work recipient, a criminal, a suspect, a witness, a victim, a reporter or a visitor. The feature of this training is anonymous in name, tile, and icon to carry out a designed scenario.

An implementation example of VPIE Community training can be illustrated through the online activities after the learning of Unit 4 Criminal Investigation of English for Elite Police (Zhongwen, 2009). Classroom learning includes explanation, listening comprehension, speaking practice, writing, translating and reading of the contents on criminal investigation, 110 dispatching, answering to a crime reporting, establishing a criminal case, questioning a witness, and interrogating a suspect. A trainee logins the group and finds at least one partner to start the training according to five scenarios, one of which is entitled Questioning a Witness of a Robbery as shown in Table 2:

Table 2. Scenario of Questioning a Witness of a Robbery

\begin{tabular}{|c|l|}
\hline Title & \multicolumn{1}{c|}{$\begin{array}{c}\text { Questioning a Witness of a Robbery } \\
\text { (basic information a police officer needs to get from a witness of a criminal case) } \\
(5 \mathrm{minutes})\end{array}$} \\
\hline Setting & $\begin{array}{l}\text { 1. Place: At the crime scene of the robbery, Beach Road, Dalian } \\
\text { 2. Time: } 18: 30\end{array}$ \\
\hline
\end{tabular}


1. A police officer

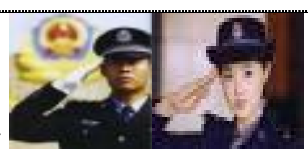

2. The witness:

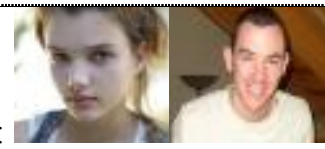

an Australian learning

Characters Chinese in Dalian

3. The victim: a young lady
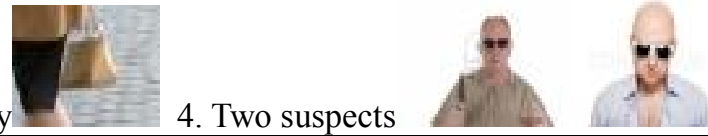

An overseas student has just witnessed a robbery on the Beach Road; a young lady was robbed by two

Plots tall bald-headed men in sunglasses and with a knife. She was so scared that she couldn't recall any more details at the moment.

Objectives 1 . Make sure about the identity of the witness. 2. Get the as much information as possible about the two suspects.

$\begin{array}{lllll}\text { 1. English proficiency } & (0.45) & \text { 2. Key words and expressions } & (0.20) & 3 . \text { Objectives achievement }\end{array}$

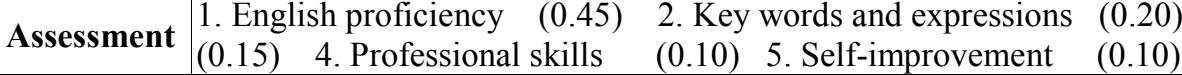

1. Questioning a witness: I understand you were the key witness for the robbery. Are you okay to

answer some questions for me? I will need to get a statement from you. Was he carrying a weapon?

What makes you say that? Can you describe him for me? I just want to get your name and phone

number. If you think of anything else, please notify us.

References 2. Describing a suspect: He was wearing sunglasses. He had a mustache. She was dressed in black.

She had a baseball cap on. Hair: short, long, shoulder length, curly, straight, spiky, brown, blond, black, red, in a ponytail

3. Background information:

https://openaccess.leidenuniv.nl/bitstream/handle/1887/13360/05.pdf?sequence $=10$

A trainee above QQ level 16 (those with level less than 16 are not allowed to choose an icon from the local pictures) can sign in the VPIE group with the registered QQ number and the password, change the icon, nickname with the icons and characters in Table 2. Figure 3 shows a trainee acting the police officer first typed, then had a voice chat with another member acting the witness:

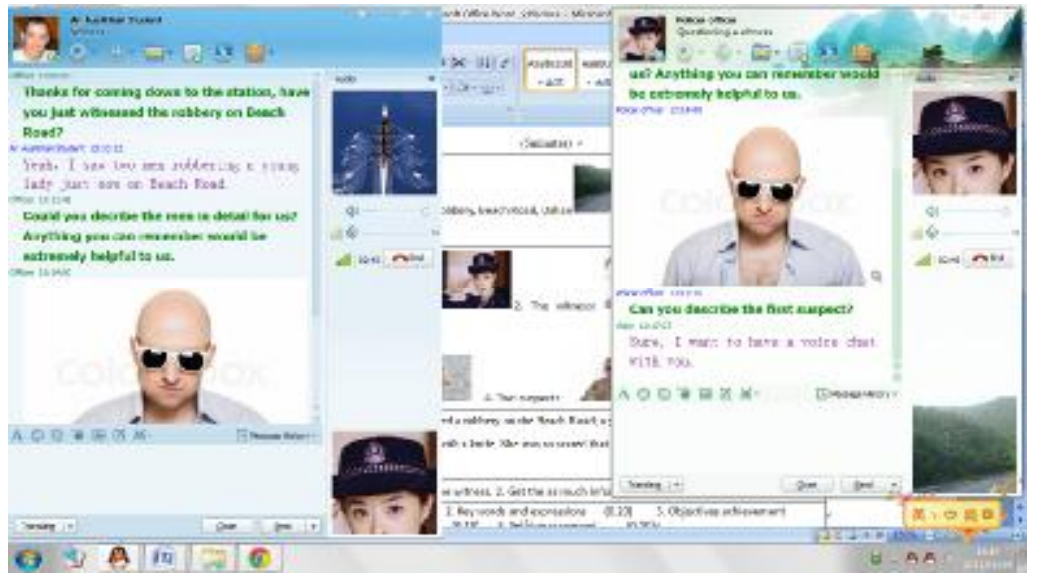

Figure 3. The "Police Officer" Is Questioning the "Witness" through Typing and Voice Chat via QQi

Voice chat is strongly encouraged to practice oral English while video chat is not recommended as anonymity can reduce the inhibition that impedes language learning (YaChun \& MauTsuen, 2008)) and can be beneficial to some students, Asian students in particular suffer from performance anxiety in real life (Hundsberger, 2009). Participants can also upload files, insert images, draw a picture, capture the screen and send it to other members, participate a group discussion or forum, keep files and references at each one's Qzone. Mentors evaluate each trainee in accordance with the quantitative assessment standards in the scenario, their average performance in several virtual policing training.

All members are free to shift from one group to the other, sharing information, discussing questions, providing feedbacks, resolving conflicts in the integrated EFL Learning Community with the common goal of supporting English competence and professional skills advancement.

\section{Results and Implications}

In Nov. 2012, the five research questions of this study were answered anonymously by 30 undergraduates majoring in Social Order of grade 2011 in their classroom after two-semester implementation of Virtual Service Learning pedagogy, who have been practicing scenario-based role-plays designed in accordance with the language point learnt in their college English textbooks either in the classroom or in the multimedia sound lab with LAN computer terminals enabling the students to interact with icons in a group; meanwhile the same survey was conducted among EFL Learning Community trainees online after 8 -month practice. The survey results are presented in Table 3 below: 
Table 3. The Survey Results

\begin{tabular}{|c|c|c|c|c|}
\hline Questions on & $\begin{array}{l}\text { 1.ways of } \\
\text { learning: } \\
\text { A. online } \\
\text { B. face-to-face } \\
\text { C. both }\end{array}$ & $\begin{array}{l}\text { 2. identity } \\
\text { preference } \\
\text { A. anonymous } \\
\text { B. real }\end{array}$ & $\begin{array}{l}\text { 3. the benefit as } \\
\text { A. an individual } \\
\text { B. a participant }\end{array}$ & $\begin{array}{l}\text { 4. the contribution to } \\
\text { A. learning interests } \\
\text { B. motivations } \\
\text { C. efficiency }\end{array}$ \\
\hline $\begin{array}{l}\text { Answers of the } \\
\text { students in the } \\
\text { classroom }\end{array}$ & $\begin{array}{l}\text { A. } 3 \% \\
\text { B. } 50 \% \\
\text { C. } 47 \%\end{array}$ & $\begin{array}{l}\text { A. } 96 \% \\
\text { B. } 4 \%\end{array}$ & $\begin{array}{l}\text { A. } 50 \% \\
\text { B. } 50 \%\end{array}$ & $\begin{array}{l}\text { A. } 43 \% \\
\text { B. } 3 \% \\
\text { C. } 54 \%\end{array}$ \\
\hline $\begin{array}{l}\text { Answers of the } \\
\text { EFL Learning } \\
\text { Community } \\
\text { trainees online }\end{array}$ & $\begin{array}{l}\text { A. } 60 \% \\
\text { B. } 20 \% \\
\text { C. } 20 \%\end{array}$ & $\begin{array}{l}\text { A. } 20 \% \\
\text { B. } 80 \%\end{array}$ & $\begin{array}{l}\text { A. } 0 \\
\text { B. } 100 \%\end{array}$ & $\begin{array}{l}\text { A. } 60 \% \\
\text { B. } 20 \% \\
\text { C. } 20 \%\end{array}$ \\
\hline
\end{tabular}

The answers to the five research questions for this study can be summarized as:

1. Learning ways of the students are influenced greatly by their habits, guidance of their teachers or tutors, and technology factors; independence and individuality should be taken into account when it comes to introducing a new learning model, transformation or combination of the traditional and the new learning methods is necessary, hybrid model seems more acceptable to most of the students.

2. Most of the students take a moderate attitude toward the exposure of their identity in a learning community both online and in real life; that is, in a face-to-face instructional background they prefer to hide their identity while in the virtual community online they tend to have their real identity revealed to some extent rather than completely concealed. The students are willing or compelled to speak English in class, because the majority of people experience communication apprehension when speaking to a group of people in a formal setting (Khairi \& Nurul, 2010), under such circumstances, students normally seek ways of hiding their identity like using icons or titles to play roles on computers in the multimedia sound lab rather than further expose their identity like speaking in front of the class. For those online learners, they don't experience such anxieties because they play the roles in a relaxed state, without so much pressure to speak at a definite time, without so many audiences sensing his or her mistakes, when they speak, they would rather let their identity known to other participants especially for those students with higher level of English proficiency to fully display their potentials. This finding seems to confirm with the past research which has consistently demonstrated that levels of moderate anxiety (versus low or high anxiety) are the most optimal for tasks such as test- taking (Edward, 1999).

3. In an online learning community, most of the participants tend to play a part in collaborative and cooperative activities; knowledge is shared or transmitted among learners as they work towards common learning goals, for example, a shared understanding of the subject at hand or a solution to a problem. Learners are not passive receptacles but are active in their process of knowledge acquisition as they participate in discussions, search for information, and exchange opinions with their peers, for knowledge is co-created and shared among peers, not owned by one particular learner after obtaining it from the course materials or instructor (Brindley et al, 2009). While in a classroom learning process, students can memorize, analyze and question independently or get involved in collective activities organized by the teacher.

4. Learning interests and efficiency are improved in EFL Learning Community; their interests are aroused to interact with "mysterious" partners, whose personality, language fluency is there for him or her to explore. As Confucius said that "learning knowledge is inferior to loving it, loving the knowledge is inferior to enjoying it", another influential philosopher in the Chinese history, Xun $\mathrm{Zi}$, also believed that "Hearing knowledge is better than ignoring it, seeing knowledge is better than hearing it, understanding knowledge is better than seeing it, applying knowledge is better than understanding it. Applying knowledge is the ultimate goal of learning". Improved interests and efficiency, in essence, is the inexhaustible power to promote learning, push researchers and teachers forward regardless obstacles from time to time.

5. Despite some of the above mentioned advantages, disadvantages of the program identified through observations, interviews and surveys include: first of all, students are sometimes disappointed by poor Internet service on campus or unsuitable instructional design, like the complexity to change icons, nicknames for a new VPIE training. Secondly, funds are inadequate to keep a technology-based research program running; and there is still a long way to go in administrative support from the authority and collaboration from almost every staff involved to guarantee curricular implementation and student participation. Thirdly, persist contribution of every member is becoming necessary to dedicate opinions, resources and energy, especially to the construction of the scenario base. Lastly, the trend of moderate anonymity calls for further in-depth study, possible solutions include indication of the user's language level, status ranks in the virtual training, and application of technologies like Virtual Reality, 3D animation and so on. 
College EFL Learning Community is a novel application of the free online messaging tool QQ International based on designed scenarios with the highlight focusing on the students' future work competence. But our study is insufficient currently to provide further details like how students of different language proficiency or professional skills benefit from the program, how the mentors involved benefit from the engagement of the research program and what are the causes of some contradictory viewpoints on online learning and face-to-face learning, and high learning interests versus relatively low motivation.

Our future study will look into multi-disciplinary online training based on scenarios by integrating QQ and emerging technologies like free conferencing tools. Further investigations will focus on how to develop trainees' occupational competence in a foreign language with lasting interests and maximum efficiency.

\section{References}

Abdulrahman, A. (2010). Teaching English as a Second/Foreign Language in a Ubiquitous Learning Environment. Master diss., California State University, Chico.

Brindley, J. E., Walti, C., \& Blaschke, L. M. (2009). Creating Effective Collaborative Learning Groups in an Online Environment. The International Review of Research in Open and Distance Learning, 10(3), 1-18.

Edward, B. (1999). Fear and Anxiety, California State University Northridge. Retrieved from http://www.csun.edu/ vcpsy00h/students/fear.htm

Hundsberger, S. (2009). Arcadia: Foreign Language Learning in Second Life and the Implications for Resource Provision in Academic Libraries. Cambridge University, UK.

Karen, L. J. (2012). The Advantages of E-learning. Retrieved from http://thetrainingworld.com/articles/elearningadvantages.htm

Khairi I., A. \& Nurul L. Bt A. R. (2010). A Study on Second Language Speaking Anxiety among UTM Students. Retrieved from http://eprints.utm.my/10275/2/Nurul_Lina_Bt_Abdul_Rahman.pdf

Kirk St., A. (2007). Linguistic and Cultural Online Communication Issues in the Global Age. IGI Global.

Manzaro, R. J. (2003). What Works in School: Translating Research into Action. Alexandria, USA: Association for Supervision and Curriculum Development Publications.

Mitchell, C., \& SacKney, L. (2001). Building Capacity for a Learning Community. Canadian Journal of Educational Administration and Policy, 19(2).

Porter, L. R. (2004). Developing an online curriculum: Technologies and techniques. Hershey, PA: Idea Group. 193.

Qi, L., \& Pingguang, C. (2012). Construction of Computer Supported Collaborative Learning Platform and Application Study Based on Blog and QQ Group. Advances in Intelligent and Soft Computing, 13, 215-220.

Roberts, S. M., \& Pruitt, E. Z. (2009). Schools as professional learning communities: Collaborative activities and strategies for professional development (2nd ed.). Thousand Oaks, CA: Corwin Press.

WEI Li (2012). Construction of Seamless English Language Learning Cyberspace via Interactive Text Messaging Tool. Theory and Practice in Language Studies, 2(8), 1590-1596.

Xingang, X., Fushan, X., \& Yaoxiang, Z. (2010). Application of QQ Network Platform in Veterinary Microbiology Teaching. Journal of Animal Science and Veterinary Medicine, 4, 48-51.

YaChun S., \& MauTsuen, Y. (2008). A Collaborative Virtual Environment for Situated Language Learning Using VEC3D. Educational Technology \& Society, 11(1), 56-58.

Zhongwen, L. (2007). Application of VPIE in Professional Knowledge Practice and English Learning for Police Academy Students. International Forum of Teaching and Studies, 3(2), 23-28.

Zhongwen, L. (2012). Construction and Application of Scenarios in College EFL Learning. International Forum of Teaching and Studies, 8(2), 32-40.

Zhongwen, L. (2009). English for Elite Police. Beijing: Press of Chinese People's Public Security University.

Zhongwen, L. (2013). Virtual Policing in English: A Trainee-centered Pedagogy for Web-mediated Curricular Learning and Field Training. Journal of Software, 8(2), 344-350.

Ziad, D. B. (2001). Learning Community in Online Education. Turkish Online Journal of Distance Education, 12(4), 12-16. 